\title{
The Value of "Dialogue Events" as Sites of Learning: An exploration of research and evaluation frameworks
}

\author{
Jane L. Lehr ${ }^{\mathrm{a} *}$, Ellen McCallie ${ }^{\mathrm{b}}$, Sarah R. Davies ${ }^{\mathrm{c}}$, Brandiff R. \\ Caron $^{\mathrm{d}}$, Benjamin Gammon ${ }^{\mathrm{e}}$ and Sally Duensing ${ }^{\mathrm{b}}$ \\ ${ }^{\mathrm{a}}$ California Polytechnic State University; ${ }^{\mathrm{b}}$ King's College London, UK; ${ }^{\mathrm{c}}$ Imperial College \\ London, UK; ${ }^{\mathrm{d}}$ Virginia Polytechnic Institute $\mathcal{E}$ State University; ${ }^{\mathrm{e}}$ Ben Gammon \\ Consulting, UK
}

In the past five years, informal science institutions (ISIs), science communication, advocacy and citizen action groups, funding organizations, and policy-makers in the UK and the USA have become increasingly involved in efforts to promote increased public engagement with science and technology (PEST). Such engagement is described as taking place within the context of a "new mood for dialogue" between scientific and technical experts and the public. Mechanisms to increase PEST have taken a number of forms. One of the most visible features of this shift towards PEST in ISIs is the organization and staging of adult-focused, face-to-face forums that bring scientific and technical experts, social scientists, and policy-makers into discussion with members of the public about contemporary scientific and socioscientific issues related to the development and application of science and technology. A significant aspect of the literature on efforts to increase PEST has focused on the development of a unifying evaluative framework for determining what counts as success for PEST mechanisms, and how success (or lack thereof) can be empirically measured. In this article, we draw from our experiences as UK-based and US-based "dialogue event" practitioners and researchers/evaluators to suggest that these existing evaluative criteria are insufficient to explore the role and value of ISI-based "dialogue events." Instead, we suggest that it may be productive to research and evaluate these ISI-based "dialogue events" as sites of learning. Secondly, however, we show through a discussion of our own research frameworks that understanding these "dialogue events" as sites of learning does not intuitively provide a framework for understanding what counts as success for these efforts. Instead, research on the role of "dialogue" within the educational literature - and the connections between "dialogue" and competing understandings of the nature of science and society-offers a multiplicity of approaches to defining the terms and goals of these events. Finally, we identify two broader implications of researching and evaluating these "dialogue events" as sites of learning for ISIs and all efforts to increase PEST. 


\section{Introduction}

In the past five years, informal science institutions (ISIs), science communication, advocacy and citizen action groups, funding organizations, and policy-makers in the UK and $\mathrm{USA}^{1}$ have become increasingly involved in efforts to promote increased public engagement with science and technology (PEST). Such engagement is described as taking place within the context of a "new mood for dialogue" between scientific and technical experts and the public (e.g., House of Lords Select Committee on Science and Technology, 2000; 108th United States Congress, 2003). Mechanisms to increase PEST have taken a number of forms. One of the most visible features of this shift towards PEST in ISIs is the organization and staging of adult-focused, face-to-face forums that bring scientific and technical experts and policy-makers into discussion with members of the public about contemporary scientific and socioscientific issues related to the development and application of science and technology (British Association for the Advancement of Science, 2005; Dana Centre/Science Museum, 2003; Gammon \& Burch, 2006; Museum of Science, Boston, 2006; National Science Foundation, 2005).

A significant aspect of the literature on efforts to increase PEST has focused on the development of a unifying evaluative framework for determining what counts as success for PEST mechanisms, and how success (or lack thereof) can be empirically measured. However, the increase in the funding and number of these ISI-based "dialogue events" (as commonly denoted by science education and communication practitioners) has received relatively little attention within the published literature on PEST. The role and value of ISI-based "dialogue events"-for event organizers, public participants, invited experts, or funding agencies-has not been theorized or examined. We also do not yet know what effect "dialogue events" have had, more broadly, in creating a culture of increased engagement. Finally, there is a need for discussion and critical thought with respect to what counts as success for these "dialogue events" - and for whom?

In this article, we draw from our experiences as UK-based and US-based "dialogue event" practitioners and researchers/evaluators to suggest that existing evaluative criteria for efforts to increase PEST are insufficient to explore the role and value of ISI-based "dialogue events." Instead, we suggest that it may be productive to research and evaluate these ISI-based "dialogue events" as sites of learning. Secondly, however, we show through a discussion of our own research frameworks that understanding these "dialogue events" as sites of learning does not intuitively provide a framework for understanding what counts as success for these efforts. Instead, research on the role of "dialogue" within the educational literature-and the connections between "dialogue" and competing understandings of the nature of science and society - offers a multiplicity of approaches to defining the terms and goals of these events. Finally, we identify two broader implications of researching and evaluating these "dialogue events" as sites of learning for ISIs and all efforts to increase PEST. 


\section{A Brief Overview of ISI-based "Dialogue Events"}

This brief overview of "dialogue events" is provided to highlight the diversity of contexts, stakeholders, and funding mechanisms that shape the practice of "dialogue events" today. At the same time, however, this overview shows that "dialogue events" can be robustly defined across this diversity of contexts as adultfocused, face-to-face forums that bring scientific and technical experts, social scientists, and policy-makers into discussions with members of the public about contemporary scientific and socioscientific issues related to the development and application of science and technology - and that these "dialogue events" are an emergent feature of informal science institutions in our countries of study, the UK and USA.

In the past five years, adult-focused "dialogue events" have become a visible and well-attended facet of informal science institutions in the UK. As highly trusted cultural institutions (National Science Board, 2004; Office of Science and Technology \& Wellcome Trust, 2000) with extensive audience reach and expertise in science communication and education, ISIs increasingly understand themselves as "hubs for dialogue and debate between scientists and the public" with the ability to "respond rapidly to new developments and science by hosting and supporting debates rather than only by creating new exhibitions" (British Association for the Advancement of Science, 2005, p. 70; see also Hirzy, 2002; Thelan, 2001). This shift towards dialogue within ISIs has occurred within the context of the broader cultural shift towards PEST, as well as in response to visitor requests for socioscientific topics to be addressed in an engaging and accessible manner for a non-specialized audience (Simonsson, 2005, 2006a,b). Finally, ISIs have been attracted to "dialogue events" and other efforts to increase PEST as an opportunity to expand and diversify their visitor demographics; that is, to move beyond their primary audience of family visitors to include adults who do not otherwise visit the institutions (Simonsson, 2005, 2006a, b).

For instance, the Dana Centre, which opened in 2000, is a purpose-built venue at the Science Museum (London) designed to provide adults with "a place for them to take part in exciting, informative and innovative debates about contemporary science, technology, and culture" (Dana Centre/Science Museum, 2003). It includes a café/bar where participants can interact both before and after events, which are held two to four times per week. Approximately $30 \%$ of the events held at the Dana Centre are classified as "dialogue events" that "aim to generate open-ended discussion between the general public, scientists, policymakers and campaigners"; "build trust, understanding, an empathy between the public, scientists, and policymakers"; and "provide an opportunity for thoughtful and informed debate where participants can express and share opinions and suggestions" (Gammon \& Burch, 2006, p. 3). ${ }^{2}$ Iterative processes of model building and evaluation have been integral to the development of dialogue-based, contemporary science programming at the Dana Centre since its inception. For a discussion of this ongoing process, see McCallie et al. (2007). The Darwin 
Centre at the Natural History Museum (London) and Explore-at-Bristol, among other UK ISIs, also organize regular "dialogue events" aimed at adults. Non-ISI organizations in the UK also regularly facilitate "dialogue events." For instance, the Café Scientifique network in the UK now includes over 30 different sites that seek to provide a "forum for debating science issues," all "for the price of a cup of coffee or a glass of wine" to "promote public engagement with science and to mak[e] science accountable" (Café Scientifique, 2006). First held in Leeds in 1998, these events occur at cafés, bars, restaurants, and theatres. Sponsors for "dialogue events" inside and outside ISIs in the UK include the Wellcome Trust, the British Council, the British Association for the Advancement of Science, and the Royal Society under the broad heading of supporting PEST.

Overall, ISIs in the USA have not been as involved in staging "dialogue events" as their UK counterparts. However, this is changing. For instance, the Museum of Science, Boston, is currently offering an experimental program called "Forum" that seeks to provide "an opportunity for people with a variety of perspectivesexperts and non-experts alike-to explore each other's views and share information" about "the impact of science and technology on the individual, society, and the environment" (Museum of Science, Boston, 2006; see also: Boyd, 1999; Davis, 2004). The new National Science Foundation-funded "Nanoscale Informal Science Education Network" (NISE) (awarded October 2005), led by the Exploratorium (San Francisco), the Museum of Science, Boston, and the Science Museum of Minnesota, provides funding for public forums "that will allow for open discussion and debate about issues related to nanotechnology" (National Science Foundation, 2005). ${ }^{3}$

However, as is the case with NISE, much of the past funding for "dialogue events" in the USA appears to have been provided on an issue-by-issue basis, rather than to support PEST more broadly. For instance, funding for the US Human Genome Project (1990-2003; coordinated by the US Department of Energy and the National Institutes of Health) required that 3-5\% of the total funding of the project was set aside to address the ethical, legal, and social implications (ELSI) of new genetic technologies. While much of the ELSI funding supported the development of programs and products directed at policy-makers, journalists, lawyers, medical practitioners, and $\mathrm{K}-12$ and post-secondary teachers, a portion of this money was directed at the "public understanding" of the human genome project and its ethical, legal, and social implications. While most of these funded projects generated products to be distributed to the public (e.g., pamphlets, newsletters, television and radio programs, web sites), this money was also used to fund "dialogue events" that occurred both inside and outside ISI settings. ${ }^{4}$ Finally, in the USA "dialogue events" have also been funded by Humanities Councils. For instance, the Choices and Challenges Project at Virginia Tech has organized a series of "dialogue events" over the past 20 years that have been partially funded by the National Endowment for Humanities and the Virginia Foundation for Humanities. 


\section{Reconceptualizing Efforts to Increase PEST: ISI-based "dialogue events" as sites of learning}

A significant aspect of the literature on efforts to increase PEST has focused on the development of a unifying evaluative framework for determining what counts as success for PEST mechanisms, and how success (or lack thereof) can be empirically measured. In this section we suggest that while ISI-based "dialogue events" are understood by event organizers, public participants, invited experts, and funding agencies as an effort to support increased PEST, the existing PEST evaluative criteria are insufficient to explore the role and value of ISI-based "dialogue events." Instead, we suggest that it may be productive to research and evaluate these ISIbased "dialogue events" as sites of learning.

Based on an extensive review of research and evaluation literature on efforts to increase PEST, Rowe and Frewer (2000; revised Rowe, Marsh \& Frewer, 2004, p. 93) have identified the evaluation criteria found in Table 1. While PEST researchers have identified the need to measure multiple outcomes, the literature has consistently emphasized that visible and measurable "impact on policy" is a primary criteria of success for these efforts (Parliamentary Office of Science and Technology, 2006; Rowe \& Frewer, 2004; Rowe, Horlick-Jones, Walls, \& Pidgeon, 2005; Rowe, Marsh

Table 1. The (revised) evaluation criteria of Rowe and Frewer (2000)

\begin{tabular}{ll}
\hline Criterion & Definition \\
\hline $\begin{array}{l}\text { Acceptance criteria } \\
\text { Representativeness }\end{array}$ & $\begin{array}{l}\text { The participants should comprise a broadly representative sample } \\
\text { of the affected population. } \\
\text { The participation process should be conducted in an independent } \\
\text { (unbiased) way. } \\
\text { Thdependence }\end{array}$ \\
The participants should be involved as early as possible in the \\
process, as soon as value judgments become salient. \\
The output of the procedure should have a genuine impact on \\
policy. \\
The process should be transparent so that the relevant population \\
can see what is going on and how decisions are being made.
\end{tabular}

Source: Rowe, Marsh \& Frewer (2004, p. 93). 
\& Frewer, 2004; Wilsdon \& Willis, 2004). From this perspective, public engagement efforts that do not facilitate direct public impact on policy, such as GM Nation, are failed efforts (Rowe et al., 2005). Other agreed-upon criteria include the representativeness of participants; the early involvement of participants in the organization of the PEST project; and transparency (Rowe, Marsh \& Frewer, 2004, p. 93).

As ISI-based "dialogue events" likewise aim to increase PEST, it initially appears reasonable to employ existing PEST evaluative criteria to determine the success of these events. However, given the emphasis on "impact on policy" within the existing PEST literature, applying these criteria to ISI-based "dialogue events" would immediately position these events as failures. The majority of ISI-based "dialogue events" have no formal connection to policy-making processes. Existing efforts to develop a unifying framework for researching and evaluating PEST efforts thus fail to allow for the possibility that these ISI-based "dialogue events" have value.

Is there any value in "dialogue events" that do not seek to facilitate direct public impact on policy-making? We wish to suggest that simply applying the existing criteria developed to determine the success of more formal PEST mechanisms to these "dialogue events" is a mistake that hinders our understanding of the possible role and value of these efforts. Thus we argue that, in order to facilitate research into these ISI-based "dialogue events" and their possible value, it is necessary to demarcate between two classes of PEST mechanisms (and two sets of evaluative criteria): (1) mechanisms that seek to facilitate direct public participation in scientific and technical decision-making; and (2) mechanisms that seek to promote a broader culture of engagement in the interactions between scientific/technical experts, policy-makers, and the public but do not seek to facilitate direct public participation in policy-making.

Demarcating two classes of PEST mechanisms makes ISI-based "dialogue events" (and related efforts) visible to PEST researchers and evaluators by recognizing that these events may have value even though they do not seek to facilitate direct public participation in scientific and technical decision-making. However, it begs the question: How should we research and evaluate the second class of mechanisms to understand their possible value? In our own work, we have found it productive to research and evaluate these ISI-based "dialogue events" as sites of learning.

We recognize that conceptualizing "dialogue events" and other public engagement efforts as sites of learning may seem dangerous in the context of the failure of the "deficit model" associated with efforts to increase the public understanding of science in the 1980s and 1990s. This model began with "an apparent assumption of 'public ignorance' in matters of science and technology" (Irwin \& Wynne, 1996, p. 6). Public controversies over science and technology were thus understood to be "created by inadequate public understandings rather than the operation of science itself" (Irwin \& Wynne, 1996, p. 6). As Irwin and Wynne suggest, the deficit or "public ignorance" model of public understanding of science "creates boundaries between the public and science and scientific institutions, and focuses the attention 
of analysts, policymakers, the news media, science educators, and so on, only on the problematic/problematised public_-begging the question, 'just why aren't the public more responsive?"' (1996, p. 6). Two additional assumptions were present in the deficit model: (1) science was assumed to be "an important force for human improvement, ... offering a uniquely privileged view of the everyday world," and (2) science was always described and imagined as a value-free and neutral activity (Irwin \& Wynne, 1996, p. 6).

Within the context of the public understanding of science movement, the solution to public ignorance was to increase scientific literacy through science education. Today in the UK, the deficit model has-in theory, at least-been firmly rejected in response to a series of crises in the public trust of science and the government in the 1990s (e.g., the BSE and genetically modified foods controversies), and a "new mood for dialogue" between scientists, policy-makers, and various publics has emerged as its replacement (House of Lords Select Committee on Science and Technology, 2000). Dialogue has thus replaced education as the goal with the shift from public understanding of science to PEST. Is it therefore wise to reintroduce the idea of learning into efforts to increase PEST?

To date, as we have seen, the criteria established to evaluate the success of public engagement efforts have not focused on learning. When learning is discussed, it is consistently positioned as a low-level goal of participatory mechanisms. ${ }^{5}$ For instance, Involve (2005), a public participation think-tank, ranks "inform" as the lowest level of public impact. Most efforts to evaluate the success of PEST mechanisms, as shown above, do not even include education or learning as a measurable outcome. However, in rejecting the model of education located in public understanding of science, is it necessary or appropriate to reject the possibility of learning altogether?

We believe not. In the following section of this paper, we describe the ways in which we, as UK-based and US-based "dialogue event" practitioners and researchers/evaluators, are currently integrating research on the educational value of "dialogue," "talk," and "discourse" with existing evaluation criteria for efforts to increase PEST. Our work aims to explore the role, value, and practice of PEST mechanisms that seek to promote a broader culture of engagement in the interactions between scientific/technical experts, policy-makers, and the public, but do not seek to facilitate direct public participation in policy-making - such as ISI-based "dialogue events." However, what this discussion of our own research frameworks should make clear is that understanding these "dialogue events" as sites of learning does not intuitively provide a framework for understanding what counts as success for these efforts. In fact, much is at stake in the choices we make as researchers and evaluators regarding what counts as learning in these contexts. These choices shape the ways in which we define the terms and goals of these events-and the ways in which we, as researchers and practitioners, envision what counts as an ideal relationship between scientific and technical experts, policy-makers, and the public. 


\section{Three Frameworks: Researching and evaluating "dialogue events" as sites of learning}

In this section, we describe three related but distinct approaches to researching and evaluating "dialogue events" as sites of learning, in order to show how perspectives from education can provide tools and frameworks to understand what counts as successful dialogue about socioscientific issues in contexts when dialogue is not directly linked to policy-making. However, we also make visible the ways in which existing debates within educational research about the purposes of "dialogue" encourage us to interrogate and challenge the framing assumptions of ISI-based "dialogue events that do not seek to directly inform policy.

\section{Framework 1: Collaboration and equity}

McCallie (2007a, b) has drawn from her work with ISIs and from literature on the learning sciences, science education, and museum learning to develop a framework for researching and evaluating ISI-based "dialogue events." McCallie has identified four goals in "dialogue event" mission statements and in her interviews with ISIbased "dialogue event" practitioners, which underpin her research framework. These include: (1) the promotion of collaborative talk; (2) the enhancement of equitable interactions; (3) the development of new or different understandings or knowledge; and (4) the enhancement of interest and engagement in controversial science-based issues in society (socioscientific issues). McCallie's current research primarily focuses on the first two goals, which can be understood as process goals.

McCallie defines collaborative talk as any collective verbal interaction in which participants listen, respond/refute, and build on one another's contributions in the process of exploring an idea or topic. For McCallie, equity in dialogue events includes both valuing a diversity of perspectives and contributions in terms of what is considered in the discussion, as well as valuing the diversity of people present in terms of their membership and participation as part of a community. Thus, McCallie focuses on collaboration and equity as markers of quality and success for ISI-based "dialogue events." Her understanding of collaborative talk and equity in her research is shaped by her exploration of research on classroom dialogue, sociocultural and interactional approaches to understanding learning, and socioscientific controversies.

Researchers and practitioners within the learning sciences, science education, and museum learning have increasingly highlighted the need for "dialogue," "talk," and "discourse" as a necessary component of learning as well as a process of learning (e.g., Alexander, 2005; Allen, 2002; Andriessen, 2006; Ash, 2004; Bransford, Brown, \& Cocking, 1999; Lipman, 1991; Mercer, 2000; Rowe, 2004; Sawyer, 2006). The central idea in much of this research is that one articulates, builds, and solidifies one's understandings through processes of expressing oneself and actively engaging with others. Researchers have identified various patterns of such verbal interaction, which, as a group of patterns, Sawyer (2006) refers to as collaborative 
discourse. McCallie analyzes "dialogue event" interactions for various types of talk, including collaborative discourse such as exploratory talk and argumentation.

Exploratory talk is a term used to indicate collaborative discourse that is in process, specifically talk about ideas that are not in final form (Barnes, 1975; Cazden, 2001). Mercer (1996) describes it as "occur[ing] when partners engage critically but constructively with each other's ideas" (p. 369). As dialogue events are to facilitate growth through the exchange and interaction of views and experiences, McCallie examines dialogue events for exploratory talk.

Another type of collaborative discourse that is argued to support both learning and thinking is that of argumentation (Driver, Newton, \& Osborne, 2000; Duschl \& Osborne, 2002; Sadler \& Zeidler, 2004; von Aufschnaiter, Erduran, Osborne, \& Simon, in press). Following from the analyses of structural patterns of argumentation, Toulmin (1958) suggests that argumentation has consistent types of microstructures across fields. He describes three fundamental components-data, claims, and warrants - as well as several other components. Claims are the assertions or conclusions, whether tentative or forceful, which are supported by data. Data are the evidence, the foundation on which the claim is based. Warrants are the general principles of the field that bridge data with claims, illustrating that the connection between the data and claims is an "appropriate and legitimate one" (Toulmin, 1958, p. 98). McCallie shares Duschl and Osborne's (2002) conclusion that Toulmin's model is a valuable contribution to understanding interaction. For example, Duschl and Osborne (2002) argue that the model recognizes argumentation as a highly social and contextualized process that allows for a view of the nature of science that moves beyond science as a "rhetoric of conclusions" (Schwab, 1962) or "final form" science (Duschl, 1990), in which science is presented a clean, neat, and undisputed series of discoveries. Further, Toulmin's emphasis on the importance of context in determining what counts as appropriate and acceptable data, claims, and warrants suggests that values and belief systems can be legitimate aspects of argumentation as ISI-based "dialogue events." For McCallie (2007a, b), this understanding of the nature of argumentation explicitly creates opportunities for public(s)—despite a lack of formally recognized scientific or technical expertise - to legitimately and equitably participate in "dialogue events" on controversial socioscientific issues, and provides tools to "trac[e] the quantity and quality of argumentation" (Erduran, Simon, \& Osborne, 2004, p. 916; see also Simon, Eduran, \& Osborne, 2006).

Notably, from our and McCallie's perspective, this research on "dialogue" in education rejects the teacher-centered deficit or transmission-and-acquisition model (Sawyer, 2006) of education. Instead, it takes a sociocultural approach to understanding learning in which teachers and students are understood as a community of learners, "working together with all serving as resources to the others, with varying roles according to their understanding of the activity at hand and differing (and shifting) responsibilities in the system" through multi-directional dialogue (Rogoff, Matusov, \& White, 1996, p. 397). In this context, understanding "dialogue events" as sites of learning forces analytical attention to the interaction (Greeno, 2006) among the public(s) and invited scientific, technical, social science, and policy 
experts. In fact, this perspective also allows the researcher to explore whether public participants should be understood as experts, in a reciprocal fashion, such as on the social dimensions of emerging sciences and technologies during the "dialogue event" (following Sclove, 1995).

Finally, McCallie's research framework draws from research in science education focused on socioscientific controversies (Barron, 2000; Jiménez-Aleixandre \& Pereiro-Munoz, 2002; Kolstø, 2001a, b; Millar \& Osborne, 1998; Patronis, Potari, \& Spiliotopoulou, 1999; Pedretti, 1999; Ratclliffe \& Grace, 2003; Sadler \& Zeidler, 2003; Zohar \& Nemet, 2002). For example, Sadler argues that research focusing on socioscientific issues addresses four themes: "(a) socioscientific argumentation, (b) relationships between nature of science conceptualizations and socioscientific decision making, (c) the evaluation of information pertaining to socioscientific issues, and (d) the influence of conceptual understanding on informal reasoning" (Sadler, 2004, p. 515). As Sadler's (2004) typology suggests, much of this research has focused on analyzing patterns of argumentation and student interaction in the context of socioscientific controversies. For instance, Jiménez-Aleixandre and Pereiro-Munoz (2002) analyzed student decision-making processes related to environmental management, and concluded that students combined conceptual knowledge, scientific evidence, and value judgments in their decision-making practices. For McCallie, these types of analyses provide ways of exploring the intersections of scientific evidence and social values apparent in discussions about socioscientific controversies at "dialogue events."

\section{Framework 2: Symmetrical individual learning through social processes}

Drawing from a similar literature to McCallie (2007a, b), supplemented by research in science communication and critical public understanding of science (see Laird, 1993; Limoges, 1993; Rip, 1986), Davies, McCallie, Simonsson, Lehr, and Duensing (in press) suggest that non-policy informing "dialogue events" can be productively understood as sites of symmetrical individual learning through social processes. Thus, in contrast to the existing focus in PEST research and evaluation literature on "impact on policy," research and evaluation efforts should focus on change at the individual rather than institutional level for these events. Notably, these researchers examine how ISI-based "dialogue events" facilitate individual change-or learning - for all those involved in the dialogue process, whether scientists, policy-makers, and the public, and define learning as more than an accumulation of facts. Drawing on both current educational literature and the literature of public participation (Cremin, 1988; Lave \& Wenger, 1999; Limoges, 1993; Rip, 1986; Rogoff, Paradise, Arauz, Correa-Chavez, \& Angelillo, 2003), for these authors learning involves emotions, empathy, and social understandings, and is an active and participatory process focused on growth in mutual understanding, awareness, and knowledge of competing perspectives on socioscientific issues as well as "facts." "Dialogue events" are thus positioned as providing opportunities for empowering individuals for further involvement, as personally beneficial for all participants 
(whether technical experts or laypeople), and as part of a gradual step-by-step change in science and society. The emphasis on symmetry in learning avoids a deficit model perspective of PEST as "educating" the public, and their conceptualization of "learning" moves the focus from the transmission of "facts" to the build up of social understandings.

For Davies et al. (in press), "dialogue events" are thus explicitly understood as sites of education for scientifically literate citizenship, in which scientific and technical experts, policy-makers, and the public are understood as citizens both challenged by and contributing to decision-making about complex socioscientific controversies. The potential strength of ISI-based "dialogue events" is the opportunity to create interactions between "those who generate scientific knowledge, those who affect its use in context, and those who experience it in daily life" to "bring to the fore the social, cultural, and moral aspects of science in society in order for them to be discussed transparently. In this way, dialogue events move beyond serving as a forum for transmission and acceptance of science to a place of problematizing and negotiating knowledge" (Davies et al., in press). "Dialogue events" are thus envisioned as part of the practice of more effective citizenship and the establishment of new relationships between science and society. They are seen as sites for change, but of change on a small-scale, which may, however, escalate into larger shifts within science and society.

Such a vision of ISI-based dialogue creates a framework for further analysis and evaluation. Contrary to previous typologies and evaluative strategies (RCUK \& Office of Science and Technology, 2005; Rowe \& Frewer, 2000, 2004, 2005), which tend to focus on large-scale impacts, this theorization of non-policy-related dialogue will lead to a focus on individual or small group interactions, experiences, and impacts. The emphasis will be on understanding how these interactions function and on evaluating whether the strict conditions of symmetry and equity are met. In fact, the entire criteria for "success" will have shifted: events that look like "failures" according to other criteria-little resolution or identifiable outcomes, a cacophony of different voices, little transfer of scientific "facts"-may, according to this schema, be viewed as successes (cf. Seifert, 2006).

\section{Framework 3: "Dialogue events" for social justice}

Lehr and Caron (2006) focus extensively on the ways in which researching and evaluating "dialogue events" as sites of learning creates an opportunity to critically examine the calls for and practices of dialogue within ISI-based public engagement efforts and to make visible underlying assumptions of event organizers, funders, and expert and public participants-paralleling critical analyses of the broader cultural shift towards public engagement (e.g., Irwin, 2001; Wynne, 2005). For instance, practitioners identify building "trust, understanding, and empathy between the public, scientists, and policy-makers" (Gammon \& Burch, 2006, p. 3) as an objective of "dialogue events" that do not seek to enable direction public participation in scientific and technical decision-making. The development of increased 
public interest in science and technology and public confidence in discussing science and technology are understood as interrelated goals. These practitioner objectives appear to parallel those of many researchers and practitioners within science education who understand the goal of science education for non-scientists to be the development of individuals who "will act as informed, responsible citizens" (Zembylas, 2005, p. 711), who are "capable of applying scientific knowledge and habits of mind" (Sadler, 2004, p. 514) in the context of socioscientific controversies.

However, within science education research, questions have been raised about whether increasing trust and confidence in science should be goal of science education for non-scientists. Lehr (2006) notes that there is nothing inherently wrong with the idea that science educators seek to train future citizens, not just future scientists. Indeed, within a world where non-scientist citizens are increasingly required to make private and public decisions about science and technology, this shift to include the needs of these future citizens within formal and informal science curricula/programs can be understood as "radical" (Osborne, 2004)—and ISI-based "dialogue events" are part of this trend. However, the problem for Lehr (2006) emerges in the model of scientifically literate citizenship located within these efforts to train "informed, responsible citizens." Critics within science education suggest that it is necessary "to examine the power relations and inequities" embedded in existing scientific knowledge and habits of mind, and to offer, as an alternative, "science teaching and learning practices that empower children, builds solidarity, and initiate change" (Zembylas, 2005, p. 710). These efforts, which Zembylas describes as "teaching science for social justice," in contrast to "science education for citizenship," focus on creating more critical relationships between science and society, focusing on changing science, not public(s). Roth and Barton (2004) have recently argued that the model of scientific literacy dominant within science education needs to be reconceptualized, suggesting that science should be understood not as "a single normative framework for rationality but merely one of many resources that people can drawn on in everyday collective decision-making processes" (Roth \& Barton, 2004, p. 158) as they engage in the struggle to create a more just and equitable world.

Following from these debates within science education, Lehr and Caron (2006) ask whether the goal of ISI-based "dialogue events" should be to increase trust between scientific and technical experts, policy-makers, and public(s) or to create more critical and oppositional perspectives? In other words, is a "bad" attitude towards science necessarily a "bad thing"? Rather than understanding the events as opportunities to increase trust between scientific and technical experts, policymakers, and public(s), Lehr and Caron (2006) explore how "dialogue events" can serve as opportunities to create more oppositional practices of non-scientist citizenship, providing non-scientist citizens with tools to question and even challenge the authority of scientific knowledge in personal and public scientific and technical decision-making practices. Research questions ask how participants understand the "dialogue event" series as a resource in decision-making practices, and seek to identify the other scientific and non-scientific resources that participants utilize to respond to socioscientific controversies and uncertainties. 
Lehr and Caron (2006) also draw from educational theory outside of science education to raise questions about the possibilities of equitable dialogue among scientific and technical experts, policy-makers, and public(s). For instance, whereas idealized models of dialogic and critical (Freire, 1972) pedagogy emphasize the educational need for inclusivity and equality among dialogue participants, critics have challenged the idea that it is even possible for actors to be situated equally within the rational public sphere that is assumed by dialogic pedagogy proponents (Ellsworth, 1989). Lehr and Caron (2006) are thus exploring whether existing power differences between scientific and technical experts, policy-makers, and public(s) can be disrupted at "dialogue events." Other critiques of dialogic pedagogy (Boler, 1999; hooks, 1994) have emphasized the need for emotion as a valued component of dialogue-whereas emotion is typically written out of calls within formal education to support dialogue, debate, and argumentation around socioscientific issues. Lehr and Caron (2006) are exploring how emotion is or is not supported at "dialogue events," as well as how conceptions of "rational" versus "irrational" function as part of their efforts to understanding how "dialogue events" function for social justice.

\section{Implications: Relationships between science and society in models of learning}

In the previous section, we have begun to explore the usefulness of researching and evaluating "dialogue events" as sites of learning by showing how we are currently employing perspectives from education to identify the value of "dialogue events" that do not seek to facilitate direct public participation in policy-making. The work we have described is currently in-progress. We recognize that what we have offered are three related but distinct frameworks for researching and evaluating "dialogue events" rather than empirical findings. However, we have discussed this work-inprogress for multiple purposes. First, we wished to show the potential fruitfulness of understanding "dialogue events" as sites of learning in the development of research frameworks and to evaluative criteria to assess PEST mechanisms that do not seek to facilitate direct public participation in policy-making. Second, however, we sought to trouble the idea that understanding these "dialogue events" as sites of learning intuitively provides a framework for understanding what counts as success for these efforts. Instead, as we have shown, adopting different perspectives from educational literatures creates different models of success.

The models of learning and the associated visions of the "ideal" outcomes for ISIbased "dialogue events" that are embedded in the three research frameworks discussed above share many similarities. These include an understanding of all participants in ISI-based "dialogue events" as both (potential) learners and contributing experts, and an understanding of "dialogue events" as a site for renegotiating the relationship between science and society. Where our frameworks differ is in the ways in which we envision the outcomes of this renegotiation. That is fitting, however, as it is the dialogue participants, themselves, who have the potential to 
collaboratively determine the regulations of the new, emerging relationships between scientific and technical experts, policy-makers, and public(s). It is our responsibility as scholars/practitioners researching and evaluating ISI-based "dialogue events" as sites of learning to make explicit how our own commitments regarding the ideal relationship between science and society shape the questions we ask and the educational theories we employ.

\section{Implications for Informal Science Institutions}

We wish to note one final intersection in the three research frameworks discussed above. Each approach points to the possibility of reshaping our understanding of the role of informal science institutions in society. McManus (1992) identifies three generations of ISIs. Here, we suggest that a "fourth generation" of ISIs may be emerging. According to McManus (1992), the first generation of ISIs were objectbased and were typically private or elite collections of objects and specimens from the natural world, as well as artifacts, such as early scientific instruments. Many of these collections were originally created as "cabinets of curiosity" (Janousek, 2000; McManus, 1992; Melber \& Abraham, 2002; Orosz, 1990). As an Enlightenment project, this generation of ISIs emphasized the collection and classification of the natural world for the purpose of research and the production of natural knowledge (Allmon, 1994; Hooper-Greenhill, 1991). In the eighteenth and nineteenth centuries, many of these exhibitions were "opened" to the public. This resulted in the positioning of ISIs as "experts in mediation between the esoteric world of science and that of the public" (MacDonald, 1998, p. 13). However, the understanding of ISIs as curated collections of objects remained in this transition to an educational mission.

The second generation of ISIs shifted from objects in the natural world to objects created by advances in science and industry (McManus, 1992). While still objectbased, the new narrative of this generation of ISIs emphasized the industrial progress of human society as a strategy to affirm and increase public acceptance and support for science and technology, particularly in the post-World War II and Cold War contexts (Bradburne, 1998, p. 239). This new emphasis paralleled efforts in formal science education to train future non-scientist citizens to appreciate and support science and scientists during the same time period (Rudolph, 2002). Collection, conservation, and research remained important aspects of this generation, in addition to public education.

The third generation of ISIs emerged in the 1960s and 1970s with the advent of science centers. For McManus (1992), third-generation ISIs represented a move from objects-based exhibits to scientific concept or phenomena-based exhibits. A pedagogical shift also occurred from a transmission or didactic model of education to a constructivist model that "regard[ed] the learner as an active participant in the construction of new knowledge and understanding" (Johnson, 2005). Ansel describes three factors that distinguish science centers from previous museums: "1) They show real phenomena and allow for real experiences, 2) they do so in an 
enjoyable, unstructured, highly social setting and 3) they provide teaching props, models and programs which visitors are unlikely to encounter elsewhere" (Ansel, 2003, p. 3). The third generation of ISIs challenged many of the assumptions about the role and value of ISIs found in the two earlier generations, and now many ISIs that can be classified as first or second generation have incorporated elements of the science center approach. However, while a shift did occur in the pedagogical model employed-from training geared towards "knowing lots of science" to "thinking like a scientist"- the authority of scientific knowledge remains unchallenged even within the third generation of ISIs.

What is the future of ISIs? Shifts have already occurred to complicate McManus' three-generation categorization. For instance, Pedretti (2004) has identified a new category of exhibits at science centers that "critically explore the nature of science and the relationship among science, technology, society, and environment." Critical issues-based exhibits "invit[e] visitors to consider such scientific material from a variety of perspectives, engage in decision-making and healthy debate of complex issues, and critique the nature and practice of science and technology" (Pedretti, 2004, p. S36). Rennie and Stocklmayer suggested that a shift by ISIs to include "'science and technology's engagement with the public' may represent the way forward" (2003, p. 768) in the future development of ISIs. However, they also noted that "It is very difficult at this time to make predictions about how this can happen" (Rennie \& Stocklmayer, 2003, p. 768).

We suggest here that understanding "dialogue events" as sites of learning may provide us with a way to understand how ISIs can become more involved, through their programming and exhibits, in increasing PEST. However, this shift necessitates more than simply the addition of socioscientific controversies to the existing content of ISIs (whether object or concept-based). Instead, if the efforts of ISIs to support increased public engagement that is not linked to policy-making are to have value, then they must involve the incorporation of new understandings of learning, focused on symmetry and mutuality. The possibility exists for ISIs to operate not as (only) storehouses of knowledge, but as sites for the production of new knowledge through dialogic engagement between scientists, policy-makers, and the public. ISIs have the opportunity to function as a resource for the production of this new knowledge by bringing together and training scientists, policy-makers, and the public in how to interact dialogically, contributing their own expertise on science, technology, and education to the discussions, and creating the possibility of a space within the broader culture for public dialogue to take root.

\section{Implications for Efforts to Increase Public Engagement with Science and Technology}

There is a second important implication of researching and evaluating "dialogue events" as sites of learning. Efforts to identify the educational value of PEST mechanisms that do not seek to facilitate direct public participation in policy-making also raise the question of whether learning should function as an evaluative criterion for those efforts that do seek to facilitate direct public impact. 
As we hope to have shown in the body of the paper, learning can be understood as more than a simplistic transmission-and-acquisition model of teaching and learning. Examining the effect of "dialogue events" in creating an opportunity for symmetrical or mutual learning on the part of scientists, policy-makers, and the public is a useful mode of research and evaluation for non-policy informing efforts. What of the PEST mechanisms that do seek to facilitate direct public participation in scientific and technical decision-making, however? In conclusion, we wish to make one final suggestion: more is at stake in PEST mechanisms that seek to facilitate direct public participation in policy-making than a particular policy or decision. What is at stake, as well, is the possibility of a broader culture of engagement in the interactions between scientific/technical experts, policy-makers, and the public. Understanding all PEST efforts as potential sites of learning may be a productive way to explore ways to support the broader cultural transformation we wish to see.

\section{Acknowledgements}

This material is based partially upon work supported by the US National Science Foundation under Grant No. 0119787 to the Center for Informal Learning and Schools. Any opinions, findings, conclusions or recommendations expressed in this material are those of the authors and do not necessarily reflect the views of the National Science Foundation. The authors also wish to thank the co-editors of this special issue and the two anonymous reviewers for their insightful commentary on earlier drafts.

\section{Notes}

This article emerged in the context of ongoing dialogue and collaboration between the authors, who are researchers and practitioners engaged in attempts to create, manage, evaluate, and analyze "dialogue events" in the UK and USA. The Center for Informal Learning and Schools has provided the opportunity and medium to link the research and practice of "dialogue events" by providing support for postgraduate students and post-doctoral researchers at King's College London to enter into collaborative relationships with practitioners at three different "dialogue event" sites: the Dana Centre at the Science Museum (London), the Darwin Centre at the Natural History Museum (London), and the Choices and Challenges Project at Virginia Tech (Blacksburg, VA, USA). The explorations in this article are thus grounded in the authors' experiences in these two national contexts, as well as by the four overarching and interconnected themes of CILS research: (1) the means and structures of participating in informal learning; (2) the use of explanation, communication, and discourse in informal contexts in a range of settings; (3) the organizational structures, policies, and agencies of those engaged in informal learning and their implications for practice; and (4) learning environments and their design.

1. For the purposes of this article, we limit our discussion to the UK and USA. However, we should note that efforts to increase PEST are not limited to Anglo-American contexts.

2. Roughly $60 \%$ of the Dana Centre events focus on increasing awareness and interest in contemporary science through techniques such as forum theater, interactive panelist debates, handling sessions using real objects from the museum's collection, art installations, and science comedy events. The other $10 \%$ of events include deliberative discussions directly 
connected to science and technology policy-making processes (such as the current Meeting of the Minds-European Citizen's Deliberation on Brain Science).

3. Institutional partners in NISE already include: the New York Hall of Science; the Sciencenter (Ithaca, NY); the Oregon Museum of Science and Industry; the Fort Worth Museum of Science and History; the Museum of Life and Science in North Carolina; the Association of Science-Technology Centers; the Materials Research Society; Main Street Science (Cornell University); MRSEC Interdisciplinary Education Group (University of Wisconsin-Madison); and the Envision Center for Data Perceptualization (Purdue University).

4. For instance, The Exploratorium's 1995 exhibit "Diving into the Gene Pool" included a lecture and discussion series on bioethics and the Human Genome Project that was partially funded by the ELSI. However, most of the ELSI-funded dialogue events seem to have occurred outside ISI settings. For instance, in collaboration with the National Educational Foundation of Zeta Phi Beta sorority, two workshops $(1999,2000)$ were held for members of minority communities in Philadelphia and New Orleans, LA to discuss the status of genetic research and avenues for greater minority-group involvement, as well as to solicit input from minority communities on their issues and concerns. A similarly intended meeting was organized in 1997 at the University of Maryland, which included as it aims to "acquaint [participating] genome project scientists and policy-makers with the aspirations and interests of these [minority] communities"; and in 1996 at Tuskegee University. The ELSI also funded a project to "introduce Native-American tribes to the basics of genetics, genetic research" and, "in turn, inform DOE HGP managers about tribal perspectives," as well as the 1994 conference entitled "Seeking Common Ground: A Forum for People with Disabilities and Genetic Professionals."

5. The criteria employed by Guston (1999) to evaluate the first consensus conference in the USA (1997) are an exception. Guston (1999) assesses four different types of impacts, what he labels "actual impact," "general thinking," "training of knowledgeable personnel," and "interaction with lay knowledge."

\section{References}

Alexander, R. (2005). Towards dialogic teaching: Rethinking classroom talk (2nd ed.). Cambridge, UK: Dialogos.

Allen, S. (2002). Looking for learning in visitor talk: A methodological exploration. In G. Leinhardt, K. Crowley, \& K. Knutson (Eds.), Learning conversations in museums (pp. 259-303). Mahwah, NJ: Lawrence Erlbaum Associates.

Allmon, W. D. (1994). The value of natural history collections. Curator, 37(2), 83-89.

Andriessen, J. (2006). Arguing to Learn. In R. K. Sawyer (Ed.), Cambridge handbook of the learning sciences (pp. 443-460). New York: Cambridge University Press.

Ansel, J. (2003). Real, simple and new. The Informal Learning Review, 63, 1-12.

Ash, D. (2004). Reflective scientific sense-making dialogue in two languages: The science in the dialogue and the dialogue in the science. Science Education, 88, 855-884.

Barnes, D. (1975). From communication to curriculum. Harmondsworth, UK: Penguin Books.

Barron, B. (2000). Achieving coordination in collaborative problem solving groups. The fournal of the Learning Sciences, 9(4), 403-436.

Boler, M. (1999). Feeling power: Emotions in the classroom. New York/London: Routledge.

Boyd, W. L. (1999). Museums as centers for controversy. Daedalus fournal of the American Academy of Arts and Sciences, 128(3), 185-228.

Bradburne, J. M. (1998). Dinosaurs and white elephants. The science center in the twenty-first century. Public Understanding of Science, 7, 237-253.

Bransford, J. D., Brown, A. L., \& Cocking, R. R. (Eds.). (1999). How people learn: Brain, mind, experience, and school. Washington, DC: National Academy of Sciences. 
British Association for the Advancement of Science. (2005). Connecting science: What we know and what we don't know about science in society. London: British Association for the Advancement of Science.

Café Scientifque. (2006). Café scientifique. Retrieved 30 March, 2006, from http://www.cafescientifique.org

Cazden, C. (2001). Classroom discourse: The language of teaching and learning (2nd ed.). Portsmouth, $\mathrm{NH}$ : Heinemann.

Cremin, L. A. (1988). American education, the metropolitan experience, 1876-1980. New York: Harper and Row.

Dana Centre/Science Museum. (2003) Dana Center: About us. Retrieved 12 March, 2006, from http://www.danacentre.org.uk/about.asp

Davies, S. R., McCallie, E., Simonsson, E., Lehr, J. L., \& Duensing, S. (in press). Discussing dialogue: Perspectives on the value of science dialogue events that do not inform policy. Public Understanding of Science.

Davis, T. H. (2004). Report: Engaging the public with science as it happens: The Current Science and Technology Center at the Museum of Science, Boston. Science Communication, 26(1), 107-113.

Driver, R., Newton, P., \& Osborne, J. (2000). Establishing the norms of scientific argumentation in classrooms. Science Education, 84, 287-312.

Duschl, R. (1990). Restructuring science education. The importance of theories and their development. New York: Teachers College Press.

Duschl, R., \& Osborne, J. (2002). Supporting and promoting argumentation discourse in science education. Studies in Science Education, 38, 39-72.

Erduran, S., Simon, S., \& Osborne, J. (2004). Tapping into argumentation: Developments in the application of toulmin's argument pattern for studying science discourse. Science Education, 88(6), 916-933.

Ellsworth, E. (1989). Why doesn't this feel empowering? Working through the repressive myths of critical pedagogy. Harvard Educational Review, 59(3), 297-324.

Freire, P. (1972). Pedagogy of the oppressed. Harmondsworth, UK: Penguin.

Gammon, B., \& Burch, A. (2006). A guide for successfully evaluating science engagement events. In J. Turney (Ed.) Engaging science: Thoughts, deeds, analysis and action. (pp. 80-85). London: The Wellcome Trust.

Greeno, J. (2006). Learning in activity. In R. K. Sawyer (Ed.), Cambridge handbook of the learning sciences (pp. 179-196). New York: Cambridge University Press.

Guston, D. H. (1999). Evaluating the first U.S. consensus conference: The impact of the citizens' panel on telecommunications and the future of democracy. Science, Technology E Human Values, 24(4), 451-482.

Hirzy, E. (2002). Mastering civic engagement: A challenge for museums. Washington, DC: American Association of Museums.

hooks, b. (1994). Teaching to transgress: Education as the practice of freedom. New York: Routledge.

Hooper-Greenhill, E. (1991). Museum and gallery education. Leicester, UK: Leicester University Press.

House of Lords Select Committee on Science and Technology. (2000). Science and society ( $3^{\text {rd }}$ Report: HL Paper 38). London: Her Majesty's Stationary Office.

Involve. (2005). People and participation: How to put citizens at the heart of decision-making. Retrieved from http://www.involving.org/index.cfm?fuseaction=main. viewSection\&intSectionID $=400$

Irwin, A. (2001). Constructing the scientific citizen: Science and democracy in the biosciences. Public Understanding of Science, 10, 1-18.

Irwin, A., \& Wynne, B. (Eds.). (1996). Misunderstanding science? The public reconstruction of science and technology. Cambridge University Press.

Janousek, I. (2000). The "context museum": Integrating science and culture. Museum International, 52(4), 21-24. 
Jiménez-Aleixandre, M. P., \& Pereiro-Munoz, C. (2002). Knowledge producers or knowledge consumers? Argumentation and decision making about environmental management. International fournal of Science Education, 24(11), 1171-1190.

Johnson, C. (2005). Science centers as learning environments. Retrieved February 15, 2006 from http://www.astc.org/resource/education/johnson_scicenter.htm

Kolstø, S. D. (2001a). “To trust or not to trust": Pupils' ways of judging information encountered in a socio-scientific issue. International fournal of Science Education, 23: 877-901.

Kolstø, S. D. (2001b). Scientific literacy for citizenship: Tools for dealing with the science dimension of controversial socioscientific issues. Science Education, 85, 289-310.

Laird, F. N. (1993). Participatory analysis, democracy, and technology decision-making. Science, Technology \& Human Values, 18(3), 341-361.

Lave, J., \& Wenger, E. (1999). Legitimate peripheral participation in communities of practice. In R. McCormick \& C. Paechter (Eds.), Learning and knowledge. Milton Keynes, UK: Open University Press.

Lehr, J. L. (2006). Social justice pedagogies and scientific knowledge: Remaking citizenship in the nonscience classroom. Unpublished doctoral dissertation, Virginia Tech, Blacksburg, VA, USA.

Lehr, J. L., \& Caron, B. R. (2006). Dialogue events as resources for personal and public decisionmaking. Paper presented at the National Association for Research in Science Teaching International Conference: Learning in Informal and Formal Contexts, San Francisco, CA.

Limoges, C. (1993). Expert knowledge and decision-making in controversy contexts. Public Understanding of Science, 2(4), 417-426.

Lipman, M. (1991). Thinking in education. Cambridge, UK: Cambridge University Press.

MacDonald, S. (1998). Exhibitions of power and powers of exhibition: an introduction to the politics of display. In S. MacDonald (Ed), The politics of display: Museums, science, culture (pp. 1-24). New York/London: Routledge.

McCallie, E. (2007a). Are they really talking to each other? In-depth analyses of dialogue events on socio-scientific issues for adults at ISIs. Paper presented at the National Association for Research in Science Teaching (NARST) International Conference, New Orleans, April 15-18.

McCallie, E. (2007b). Examining dialogue at public engagement events on socio-scientific issues among adults in informal learning contexts. Paper presented at American Educational Research Association (AERA) Annual Meeting, Chicago, IL, April 9-13.

McCallie, E., Simonsson, E., Gammon, B., Nilsson, K., Lehr, J. L., \& Davies, S. (2007). Learning to generate dialogue: Theory-practice-evaluation. Museums \& Social Issues, 2(2), 167-186.

McManus, P. (1992). Topics in museums and science education. Studies in Science Education, 20, 157-182.

Melber, L. M., \& Abraham, L. M. (2002). Science education in U.S. natural history museums: A historical perspective. Science and Education, 11, 45-54.

Mercer, N. (1996). The quality of talk in children's collaborative activity in the classroom. Learning and Instruction, 11, 45-54.

Mercer, N. (2000). Words and minds. How we use language to think together. London: Routledge.

Millar, R., \& Osborne, J. (Eds.). (1998). Beyond 2000: Science education for the future. London: King's College London.

Museum of Science, Boston. (2006). Welcome to forum at Museum of Science, Boston! Retrieved August 1, 2006, from: http://www.mos.org/doc/1938

National Science Board. (2004). Science and engineering indicators. Washington, DC: National Science Board.

National Science Foundation. (2005). New grants are awarded to inform the public and explore the implications of nanotechnology. Retrieved March 30, 2006, from http://www.nsf.gov/news/ news_summ.jsp?cntm_id=104505\&org=NSF\&from=news

Office of Science and Technology \& the Wellcome Trust. (2000). Science and the public: A review of science communication and public attitudes to science in Britain. Retrieved March 30, 2006, from http://www.wellcome.ac.uk/doc_WTD003420.html 
Orosz, J. J. (1990). Curators and culture: The museum movement in America, 1740-1870. Tuscaloosa, AL University of Alabama Press.

Osborne, J. (2004). Science education for all: Radical vision or hopeless fantasy? King's College London Inaugural Lecture. Retrieved March 30, 2006 from http://www.kcl.ac.uk/depsta/ education/hpages/josborne.html

Parliamentary Office of Science and Technology. (2006). Debating science. Postnote, 260, 1-4.

Patronis, T., Potari, D., \& Spiliotopoulou, V. (1999). Students' argumentation in decision-making on a socio-scientific issue: Implications for teaching. International fournal of Science Education, $21,745-754$.

Pedretti, E. (1999). Decision making and STS education: Exploring scientific knowledge and social responsibility in schools an science centers through an issues-based approach. School Science and Mathematics, 99, 174-181.

Pedretti, E. (2004). Perspectives on learning through research on critical issues-based science center exhibitions. Curriculum, Teaching and Learning, 88, S34-S37.

Ratcliffe, M., \& Grace, M. (2003). Science education for citizenship: Teaching socio-scientific issues. Maidenhead, UK: Open University Press.

RCUK \& Office of Science and Technology. 2005, Evaluation: Practical guidelines. Swindon, UK: RCUK.

Rennie, L. J., \& Stocklmayer, S. M. (2003). The communication of science and technology: Past, present, and future agendas. International Fournal of Science Education, 25(6), 759-773.

Rip, A. (1986). Controversies as informal technology assessment. Knowledge: Creation, Diffusion, Utilization, 8(2), 349-371.

Rogoff, B., Matusov, E., \& White, C. (1996). Models of teaching and learning: Participation in a community of learners. In D. R. Olson \& N. Torrance (Eds.), The handbook of education and human development (pp. 388-414). Oxford, UK: Blackwell.

Rogoff, B., Paradise, R., Arauz, R. M., Correa-Chavez, M., \& Angelillo, C. (2003). Firsthand learning through intent participation. Annual Review of Psychology, 54, 175-203.

Roth, M. W., \& Barton, A. C. (2004). Rethinking scientific literacy. New York \& London: RoutledgeFalmer.

Rowe, S. M. (2004). Discourse in activity and activity as discourse. In R. Rogers (Ed.), An introduction to critical discourse analysis in education (pp. 79-96). Mahwah, NJ: Lawrence Erlbaum Associates.

Rowe, G., \& Frewer, L. J. (2000). Public participation methods: A framework for evaluation. Science, Technology \& Human Values, 25(1), 3-29.

Rowe, G., \& Frewer, L. J. (2004). Evaluating public participation exercises: A research agenda. Science, Technology \& Human Values, 29(4), 512-556.

Rowe, G. \& Frewer, L. J. (2005). A typology of public engagement mechanisms. Science, Technology E Human Values, 30(2), 251-290.

Rowe, G., Marsh, R. \& Frewer, L. J. (2004). Evaluation of a deliberative conference. Science, Technology and Human Values, 29(1), 88-121.

Rowe, G., Horlick-Jones, T., Walls, J., \& Pidgeon, N. (2005). Difficulties in evaluating public engagement initiatives: Reflections on evaluation of the U.K. GM Nation? Public debate about transgenic crops. Public Understanding of Science, 14, 331-352.

Rudolph, J. (2002). Scientists in the classroom: The cold war reconstruction of American science education. New York: Palgrave.

Sadler, T. D. (2004). Informal reasoning regarding socioscientific issues: A critical review of research. Fournal of Research in Science Teaching, 41(5), 513-536.

Sadler, T. D., \& Zeidler, D. L. (2003). The morality of socioscientific issues: Construal and resolution of genetic engineering dilemmas. Science Education, 88, 4-27.

Sadler, T. D., \& Zeidler, D. L. (2004). Student conceptualizations of the nature of science in response to a socioscientific issue. International fournal of Science Education, 26(4), 387-409. 
Sawyer, R. K. (2006). Analyzing collaborative discourse. In R. K. Sawyer (Ed.), Cambridge handbook of the learning sciences (pp. 187-204). New York: Cambridge University Press.

Sclove, R. (1995). Democracy and technology. New York: Guildford Press.

Schwab, J. J. (1962). The teaching of science as enquiry. Cambridge, MA: Harvard University Press.

Seifert, F. (2006). Local steps in an international career: A Danish-style consensus conference in Austria. Public Understanding of Science, 15(1), 73-88.

Simon, S., Erduran, S., \& Osborne, J. (2006). Learning to teach argumentation: Research and development in the science classroom. International fournal of Science Education, 28(2-3), 235-260.

Simonsson, E. (2005). The Dana Centre audience research: 2004-2005. London: National Museum of Science Industry.

Simonsson, E. (2006a). The Dana Centre audience research: 2005-2006. London: National Museum of Science Industry.

Simonsson, E. (2006b). Developing audience-led events at the Dana Centre-What have we learned so far? Paper presented at the 19th Annual Visitor Studies Association Conference, Grand Rapids, MI.

Thelan, D. (2001). Learning community: Lessons in co-creating the civic museum. Museum News, $80(3), 56-95$.

Toulmin, S. (1958). The uses of argument. Cambridge: Cambridge University Press.

108th United States Congress. (2003). 21 ${ }^{\text {st }}$ century nanotechnology research and development act (Public Law No. 108-153). Retrieved from http://www.theorator.com/bills108/s189.html

von Aufschnaiter, C., Erduran, S., Osborne, J., \& Simon, S. (in press). Arguing to learn and learning to argue: Case studies of how students' argumentation relates to their scientific knowledge. Fournal of Research in Science Teaching, 45(1).

Wilsdon, J., \& Willis, R. (2004). See-through science: Why public engagement needs to move upstream. London: DEMOS.

Wynne, B. (2005). Risk as globalizing "democratic" discourse? Framing subjects and citizens. In M. Leach, I. Scoones, \& B. Wynne (Eds.), Science and citizens: Globalisation and the challenge of engagement (pp. 66-82). London: Zen Books.

Zembylas, M. (2005). Science education: For citizenship and/or for social justice? fournal of Curriculum Studies, 37(6), 709-722.

Zohar, A., \& Nemet, F. (2002). Fostering students' knowledge and argumentation skills through dilemmas in human genetics. Fournal of Research in Science Teaching, 39, 35-62. 